EGU21-14567

https://doi.org/10.5194/egusphere-egu21-14567

EGU General Assembly 2021

(c) Author(s) 2021. This work is distributed under

the Creative Commons Attribution 4.0 License.

\title{
A multidisciplinary approach to improve and share the understanding of landslide hazard in mountain environments: the PIURO 1618 disaster
}

\author{
Enrico Pigazzi ${ }^{1}$, Tiziana Apuani ${ }^{1}$, Riccardo Bersezio ${ }^{1}$, Corrado Camera ${ }^{1}$, Alessandro Comunian ${ }^{1}$, \\ Maurizio Lualdi ${ }^{2}$, and Andrea Morcioni ${ }^{1}$ \\ 'Dipartimento di Scienze della Terra "Ardito Desio", Università degli Studi di Milano, Milano, Italy \\ ${ }^{2}$ Dipartimento di Ingegneria Civile e Ambientale, Politecnico di Milano, Milano, Italy
}

Large landslides have affected the geomorphological evolution of most Alpine territories. Some catastrophic events also had a huge impact on the economic and cultural development of human societies. In the Bregaglia Valley and in nearby territories, evidences of settlements date back to the Roman age. In these areas, human activities always coexisted with the natural evolution of the valley, which has been characterized by recurrent natural events such as floods and landslides. Among these, the 1618 Piuro landslide was the one with the strongest impact, remaining impressed on the collective imagination and artistic representations. It erased an entire village and its 1000-2000 inhabitants few km East of Chiavenna, and it is still remembered as one of the worst tragedies in the history of the region. Understanding the evolutionary dynamics of such a geomorphologically active landscape, taking notes from the ancient or recent past, plays a central role in risk assessment and mitigation. In Piuro, such dynamics were investigated through a multidisciplinary approach, starting from the historical and archaeological analyses of the event and involving: (i) the geological/geomorphological characterization of the Last Glacial Maximum, to present palimpsest landscape of the valley through the realization of thematic maps, (ii) the stratigraphic interpretation of new boreholes crossing the landslide deposits and the deeper intramountain sedimentary valley fill, (iii) the realization of topographic, petrographic, geophysical (HVSR and MASW) and geo-mechanical surveys. In addition, the implementation of numerical models is on the way, to check different hypotheses on the predisposing factors, triggers, timing and evolution of the 1618 Piuro landslide. To increase the awareness of natural hazards in mountain settings and to promote a risk and resilience culture, all these acquired knowledge will be disseminated and shared with citizen, authorities and scientists in the frame of the Interreg project A.M.AL.PI.18. The fulfilment of a transboundary (Italian-Swiss) geo-cultural path will link other sites of historical and geological relevance through the territories of Bregaglia, Valchiavenna, Moesa and Ticino. Showing and telling the history of catastrophic landslides and their impacts on the involved communities, it will contribute to enhance the perception of beauty and the awareness of geo-hazard. The dissemination of knowledge and awareness is one main goal towards risk mitigation.

The present work was co-funded through the EU, Regional Development European Fund, by Italian 
State, Helvetic Confederation and Cantons under the Interreg V-A IT-CH 2014-2020 Cooperation Program - A.M.AL.PI.2018 "Alpi in Movimento, Movimento nelle Alpi. Piuro 1618-2018", ID 594274 Axis 2 "Cultural and natural enhancement". 